\title{
Describing the issues of knowledge maragement in R\&D: towards a communication and analysis tool
}

\author{
Inge C. Kerssens-Van Drongelen, Petra C. de Weerd-Nederhof and Olaf A. M. \\ Fisscher \\ School of Management Studies, University of Twente P.O. Box 217, 7500 AE \\ Enschede, The Netherlands
}

\begin{abstract}
In this article, a comprehensive descriptive model of R\&D knowledge management is presented and its use illustrated. Knowledge is defined as: information internalized by means of research, study or experience, that has value for the organization. First, the issue of knowledge management is placed in the context of $R \& D$ management, and set alongside what has been written in R\&D management literature about topics such as information management, information technology in R\&D, technology transfer, communication and organizational learning. Then, we present our descriptive model, and apply it in a case study concerning a Dutch multinational in the chemical industry. The model served as an aid to identify bottlenecks, and was a useful starting point for formulating improvement plans, some of which are presented. The paper concludes with an evaluation of the model as a communication and analysis tool, and ideas for further improvement.
\end{abstract}

\section{INTRODUCTION}

Changes in the environment - intensified competition, a splintered mass market, shortened product life cycles, and advanced technology and automation - challenge companies to improve their Research and Development processes (Clark \& Fujimoto, 1991; Kumpe \& Bolwijn, 1994). These R\&D processes can primarily be seen as information transformation processes (Clark \& Fujimoto, 1991; Moenaert \& Souder, 1990), transforming information about client orders, market demands and technological advancements into product and process designs (Weerd-Nederhof et al., 1994). Thus, improving $R \& D$ processes will mainly have to do with either improving the quality of the information input, or improving the capacity or capability of the R\&D function to transform information into valuable output. The information input needed to develop products and processes will be partially new, coming from outside the company, but the largest part will probably be already available within the company, stored in the minds of people, in archives, in procedures, in equipment, etc. The focus of this article will be on this large internal stock of information, which we will call the 'organization's knowledge base'. More and more people agree that this knowledge base is a valuable company asset, and that enlarging the knowledge base and improving its use will contribute to the effectiveness of the R\&D process (Meyers \& Wilemon, 1989; Takeuchi \& Nonaka, 1986). However, knowledge, knowledge creation and knowledge dissemination in organizations are capricious, complex matters, which are difficult to manage. In this article we attempt to unravel the complexity of these issues by introducing a descriptive model that ties together many current insights into $R \& D$ processes, knowledge management and related subjects. We intend for this model to be the starting point for the development of a practical tool that can be used by researchers, consultants and $R \& D$ managers to assess the current situation and to uncover bottlenecks in knowledge management. Before discussing our model, we will first present our perspective of knowledge and knowledge management and position them in the context of $R \& D$ management. 


\section{KNOWLEDGE}

In the literature, 'knowledge' is a frequently used concept. Without reviewing all different kinds of knowledge concepts, we confine ourselves to giving a definition of knowledge that we have found to be useful in this respect: knowledge is information internalized by means of research, study or experience, that has value for the organization.

Thus, it is that part of the information used explicitly or implicitly in the R\&D process, which is not new, but already available somewhere within the organization, stored in the minds of people, in archives, in procedures, in equipment, etc. In a workshop on knowledge management which we organized for R\&D managers, participants supported our definition of knowledge presented above, as it adequately covered their own perspective of knowledge. The R\&D managers stressed that the experience part was very important, but also the most difficult to get a hold on. A problem with our knowledge definition is of course that it is a retrospective one: you can only be sure whether a piece of information has really been valuable for the organization after it has been used again. Beforehand, we should speak of potential knowledge, being information that is expected to be useful in the future, because it seems to have a link with the company's (long term) strategy. This stresses the necessity of looking ahead, posing high demands on the activity of sifting more durable information (knowledge) from 'onetime-use-only' information. Above all, this requires clearly defined company and $R \& D$ strategies (Debackere et al., 1994) in order to be able to anticipate future needs.

\section{R\&D STRATEGY AND KNOWLEDGE MANAGEMENT}

In our opinion, the possibilities for and barriers to accumulating and disseminating knowledge in the $R \& D$ process are largely determined by the choices made in the $R \& D$ strategy, which in its turn depends upon the business strategy and the other functional strategies within the organization. R\&D strategy is about making and implementing decisions regarding the design of the $R \& D$ function. These decisions concern the $R \& D$ performance criteria to be pursued, the operational, management and support processes, the technologies (incorporated in people, tools and equipment) needed to perform these processes, and the organizational arrangements (structure and culture) dividing and co-ordinating the processes. The Operations Strategy Framework in Fig. 1 lists these R\&D strategy elements (the last four columns) and illustrates the dependence of the R\&D strategy upon the business strategy (the first four columns) and the other functional strategies. Furthermore, Fig. 1 visualizes that $R \& D$ strategy ought to be an ongoing process of planning and designing $\rightarrow$ implementing $\rightarrow$ monitoring $\rightarrow$ learning $\rightarrow$ (re-)planning and (re-)designing etc. This framework was adapted from Weerd-Nederhof et al. (1996) who used it amongst others as a basis for a communication and analysis tool for the purpose of assessing quality in R\&D. Note that, when defining the R\&D strategy, special attention should be paid to a proper mix of, and alignment between, the so-called 'system technical' and 'social-dynamic' attributes of the strategy elements (Weerd-Nederhof et al., 1995; see Table 4, Appendix 1).

Unfortunately, in many organizations managers and researchers are not aware that some of the chosen R\&D strategy characteristics hamper or benefit knowledge building and exchange. Thus, knowledge accumulation and dissemination happens implicitly. In these situations, there is a risk that strategy changes result in unexpected loss of knowledge or reduction of knowledge transfer. In contrast with this practice, knowledge management can be defined as: the explicit influencing of knowledge accumulation and dissemination. This influencing can be done via mechanisms particularly aimed at knowledge building and dissemination (e.g. postproject evaluations), but also via mechanisms that serve multiple purposes (e.g. multifunctional project teams, central databases). Furthermore, diminishing the negative impact of certain strategy choices, such as departmental barriers, can also be seen as part of knowledge management. In the subsequent section, R\&D strategy characteristics influencing knowledge accu- 


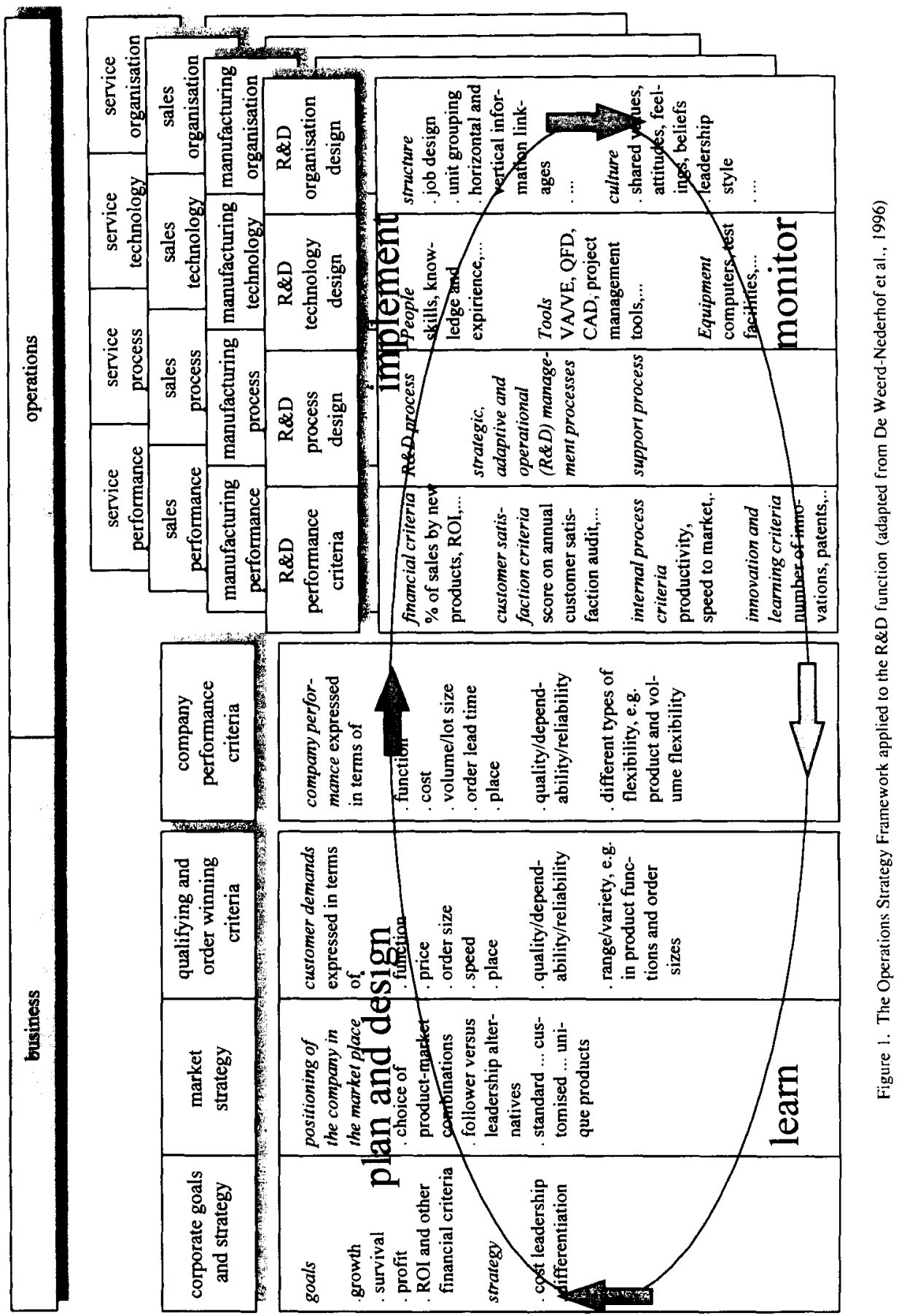


mulation and dissemination will be explored further.

\section{THEORETICAL CONCEPTS IN KNOWLEDGE MANAGEMENT}

Above we have stressed the importance of knowledge management and positioned it within the $R \& D$ management process. In this section of the article we will discuss briefly several issues, discussed in literature, that are related to knowledge management, in order to be able to place our descriptive model in the broader field of $R \& D$ management research. The issues found most relevant will be summarized, and in the next section linked together in a descriptive model.

\section{Information management}

In the introduction we defined knowledge as internalized information that has value for the organization. Note again that we make an explicit distinction between information obtained from outside that is completely new to the company, and information already internalized somewhere in the organization (but perhaps new to the user). In R\&D management literature the term 'information' normally encompasses both (e.g. Debackere et al., 1994; Johnston \& Gibbons, 1975). Both external and internalized information is necessary to carry out successful R\&D, but the appropriate mix will differ with the kind of $R \& D$ activity (innovativeness, complexity etc.) and the project phase (Allen, 1977; Katz \& Allen, 1982; Hauptman, 1986). Information is needed to reduce the external and internal uncertainty surrounding $R \& D$ activities (Moenaert \& Souder, 1990). Wheelwright \& Clark (1992) visualize the uncertainty reduction during a project as a funnel (see Fig. 4).

Spending time early in the project on information acquisition, usually benefits project success (Meyers \& Wilemon, 1989). However, in performance appraisal, quickly moving to the implementation phases (with failure repair later on) is often given higher reward than undertaking thorough groundwork (Meyers \& Wilemon, 1989). Acquisition of external and internalized information, can be done in numerous ways, e.g. by reading literature, informal communication with people in one's human network inside or outside the company, scanning databases. However, to be able to do this, one has to know where a specific piece of information may be found (traceability of a source), and have access to it (Ketley, 1994; Johnston \& Gibbons, 1975).

A topic that has drawn specific attention in literature, is the search for and acquisition of new (fuzzy) information concerning customer needs, technological and market developments, competitor actions, etc., especially in the long term. When these activities have a continuous character, they are sometimes referred to as 'business intelligence' or 'science and technology intelligence' (e.g. Ashton \& Stacey, 1995; Debackere et al. 1994). Once relevant pieces of external information are acquired and internalized, they have to be stored in the organization's knowledge base, and become potential knowledge (Ashton \& Stacey, 1995), just as internally developed information.

Another information management topic that has been thoroughly discussed in the $\mathrm{R} \& \mathrm{D}$ literature is the transfer of information/knowledge within projects from one functional discipline to another. A wide range of means and tools have been found helpful in this respect, such as (co-located) multifunctional project teams (Wheelwright \& Clark 1992), Quality Function Deployment diagrams (Hauser \& Clausing, 1988) and periodic prototyping (Wheelwright \& Clark, 1992). All these means and tools, in common, contribute to a common language and help to transform knowledge stored in brainware (and thus available to only one or a few people), into a form that can be shared by many people (groupware, documentware, hardware).

Before a piece of external or internalized information is actually applied, it will be evaluated by a user on its relevance, novelty, comprehensibility and credibility (Moenaert et al., 1992). This is of course a subjective evaluation, influenced by the perception that the user has about the quality of the source. For internal sources, this perception is largely determined by the interfunctional climate (Moenaert et al., 1992).

Summarizing the literature overview so far, we see that information management in $R \& D$ is a broader concept than knowledge 
management, as it covers both external and internalized information. In the following paragraphs, we will zoom in on three specific aspects of information management, namely the use of Information Technology (IT) in $R \& D$, technology transfer in general, and a specific transfer method that has proven to be of utmost importance in R\&D: communication. For the moment, we conclude that the following issues will have to be addressed in our descriptive model: the search for, and acquisition of, new and internalized information in R\&D projects, the means by which this is done, the evaluation and application of information (Fig. 4), and the organization's knowledge base (Fig. 3). Influential characteristics of the R\&D strategy that have to be taken into account are: the type of R\&D activity, the project phases, the performance appraisal system, the traceability and accessibility of sources, the means (tools) that facilitate information knowledge transfer, and the interfunctional climate (Fig. 5).

\section{Use of IT in $R \& D$}

IT tools such as CAD/CAE/CAM systems, analysis and simulation programs, and Product Data Management Systems, have been expected to improve the productivity of the R\&D process considerably. However, so far, the reported results are disappointing. Wheelwright \& Clark (1992) attribute this to the fact that computers are primarily used for automating existing engineering tasks. Many more benefits can be expected when IT is used to support integrated problem solving. For this purpose 'fourth generation' systems are needed, encompassing: a database (jointly owned by product designers, process engineers and marketeers), analytical tools, critical relationship diagrams and an electronic message system. However, from a small survey we conducted among the participants in our knowledge management workshop, it was clear that at the moment IT tools are hardly used in $R \& D$, neither as a medium to store knowledge, nor as a means to get insight into and access to knowledge, and also not as a means to actually convey knowledge.

From the literature cited above it can be concluded that the following IT issues should be included in our descriptive model: internalized data stored in computer databases (documentware), and the computer programs (hardware) both being part of the organizational knowledge base, IT tools (e.g. critical relationship diagrams) as a means of making stored knowledge traceable and accessible, and IT tools (e.g. e-mail) as means of conveying knowledge (Figs 3 and 4). As influential strategy characteristics we should add the volume and functionality of IT equipment (Fig. 5).

\section{Technology transfer}

Technology transfer (TT) deals with a specific part of knowledge management, namely the conveying of technology/knowledge from one party to its adoption by an other (Souder et al., 1990). In most TT literature, the focus is on the transfer of technical knowledge between different organizations or even countries. However, some of the TT concepts could also be useful within organizations. For example, Jain \& Triandis (1990) mention the following three general TT approaches:

the personnel approach: temporary or permanent transfer of the owner $(s)$ of knowledge (brainware) to the user group that has to apply the knowledge;

the organizational link-pins approach: specialized transfer agencies used as intermediaries, bringing together and supporting owners and seekers of knowledge; the procedural approach: early user involvement by means of procedures, e.g. multifunctional (lifecycle) project teams.

Souder et al. (1990) list four people roles that contribute to successful adoption of the conveyed knowledge: boundary spanners, gatekeepers, champions and angels. As organizational factors influencing transfer success, user involvement, direct responsibility of the project leader for conveying the project outputs, and transfer as an explicit goal are mentioned.

From this TT literature we can conclude that conveyance and adoption (use) of knowledge should be incorporated in our model as activities (Fig. 4). Influential strategy factors that have to be taken into account are: knowledgeable people transfer, intermediaries, multifunctional project teams, 
people roles, direct responsibility of the project leader for conveying knowledge and transfer as an explicit goal (Fig. 5).

\section{Communication}

Communication is the oral or written 'handing over' of information (including knowledge) from one person to another. Although oral communication is generally acknowledged to be a very important means for handing over information/knowledge in $\mathrm{R} \& \mathrm{D}$, it is not always the most suitable form (Johnston \& Gibbons, 1975).

As described by Brown \& Eisenhardt (1995), a whole stream of research has been dedicated to the subject of internal and external communication in R\&D. Appropriately structured task communication (both internal and external) has been found to lead to a more comprehensive and varied information flow to team members and, thus, to higher performing development processes (Brown \& Eisenhardt, 1995). Again, multifunctional project teams have been found useful in this respect. However, the frequency of communication was not found to be a predictor of success, but rather the kind of person $(s)$ (the sources) with whom the researchers communicated (Lee, 1995). Several studies (e.g. Allen, 1977; Katz \& Allen, 1982; Hauptman, 1986) report that, dependent on the type of $R \& D$, communication with specific kinds of sources are related to project success, e.g. for development projects communication with other members of the company (other R\&D departments, marketing, production, etc.), for basic research projects communication with people outside the organization, and for technical service projects communication with other team members. Katz \& Allen (1982) also found that this vital type of communication declined when the average team tenure became more than five years, probably because team members then became infected with the so-called 'Not Invented Here' syndrome. Further, Allen (1977) observed a decline in communication with an increase in the physical distance between researchers.

To summarize, not all communication is the conveying of knowledge, and knowledge transfer in R\&D should not be done solely by means of oral communication, but it is certainly the most used method. In our model, the following R\&D strategy characteristics should be included: the type of people communicated with, the type of $R \& D$, the physical distance between researchers, and team composition, especially the average team tenure (Fig. 5).

\section{Organizational learning}

The last stream of literature we will review in the context of knowledge management is that on organizational learning. We adopt as a definition of organizational learning what Fiol \& Lyles (1985) call 'cognition development', being the development of insights (knowledge). A distinction must be made between lower- and higher-level learning, also called single-loop and double-loop learning (Fiol \& Lyles, 1985; Agyris \& Schön, 1978). Lower-level learning refers to detecting and correcting errors using the existing frame of reference ('theories-inuse'). Higher-level learning on the other hand, aims at adjusting the frames of reference through the use of heuristics, skills development and insights (Fiol \& Lyles, 1985). In this respect, unlearning (adaptations of the existing knowledge base) is an important issue (Takeuchi \& Nonaka, 1986; Fiol \& Lyles, 1985). In our concept of knowledge, both lower and higher level learning take place within the $R \& D$ process, each using a specific kind of input from the knowledge base.

Another relevant topic in the organizational learning theory is the link between individual and organizational learning. As described by Kim (1993), at the heart of the organizational knowledge base is the knowledge, especially the mental models, stored in the heads of individuals (brainware). These individuals take actions and, based on the feedback they get from these actions from their environment, they may enhance or adapt their mental models (individual learning). Subsequently, what the individual has learned has to be made explicit in order to be able to carry it over to the organizational mental models (organizational learning). Meyers \& Wilemon (1989) position between these two learning domains, a team or group as a 'learning site'.

A distinction in learning processes can also be made on the basis of the subject: task 


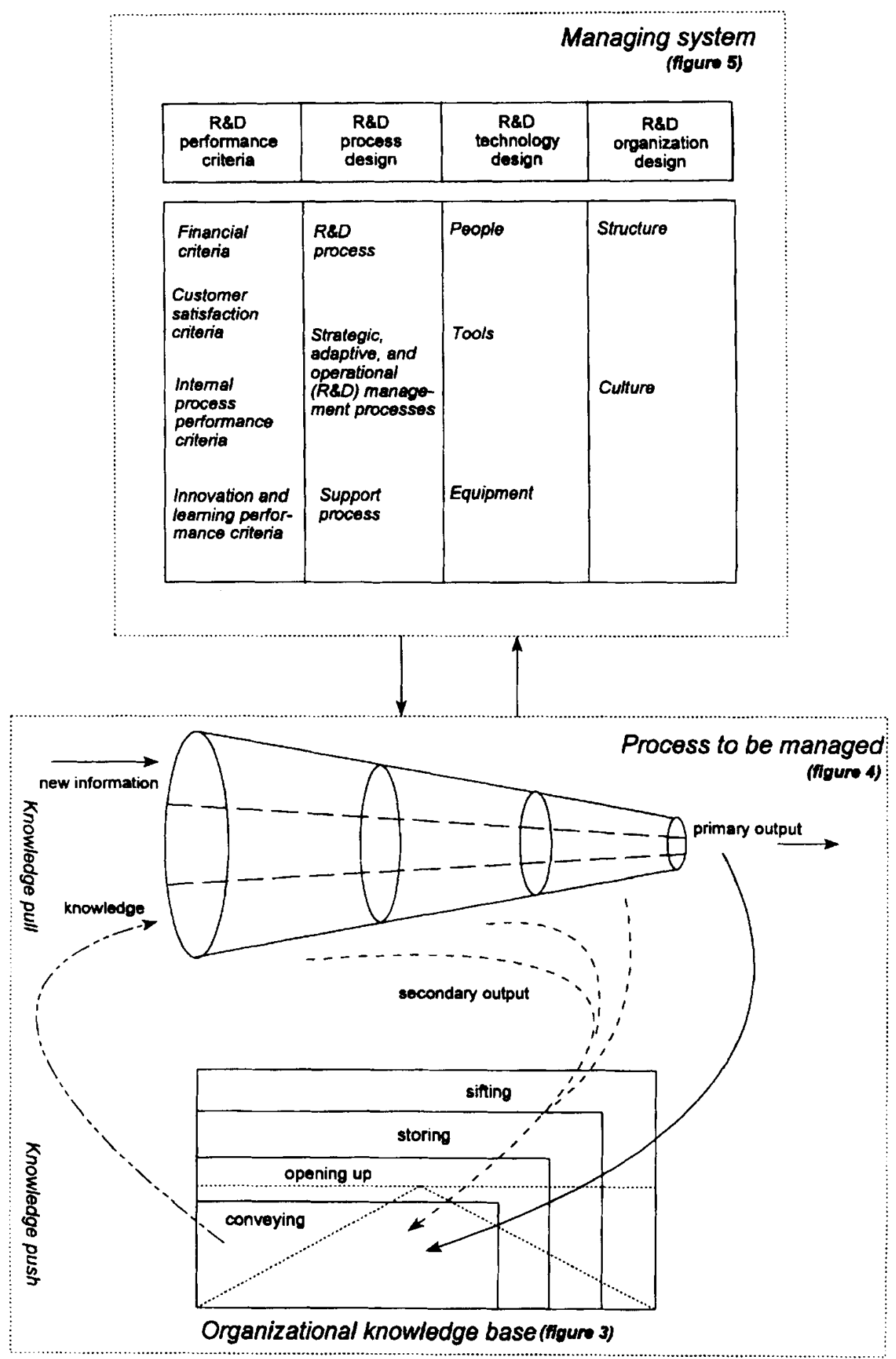

Figure 2. The basic framework of the R\&D knowledge management model 


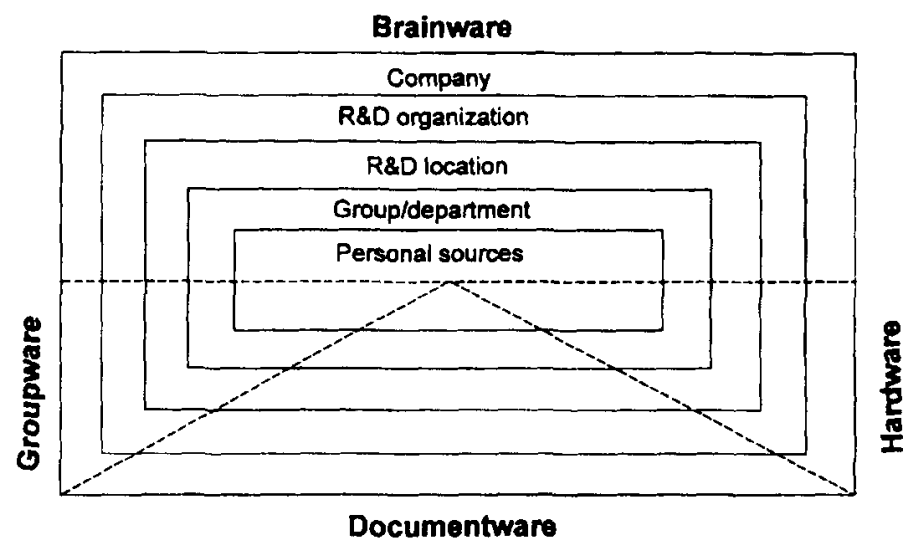

Figure 3. The organizational knowledge base

specific learning (technical, marketing etc.) versus learning about the functioning of the R\&D process as a whole (managerial learning). Both types of learning are important in R\&D. Wheelwright \& Clark (1992) state that the second kind of learning is especially difficult and often neglected as people are pressed forward to the next project. Therefore, explicitly adding an evaluation phase at the end of a project aimed at managerial learning, has been found useful (Wheelwright \& Clark, 1992).

To summarize, 'learning' should be included as an activity in our model, having as input knowledge from the knowledge base and sometimes feeding back adapted knowledge. Within this learning process knowledge is evaluated and applied (Fig. 4). Furthermore, our model of the knowledge base should have several 'levels' (individual, group, organization) and several 'kinds' of knowledge (technical, marketing, managerial, etc.) (Fig. 3). As influential R\&D strategy characteristics, feedback and an explicit project evaluation phase must be added (Fig. 5).

\section{THE DESCRIPTIVE MODEL OF KNOWLEDGE MANAGEMENT}

Based on the previously summarized literature, discussions with $R \& D$ managers during a knowledge management workshop, and observations in companies we are working with, we have developed a descriptive model encompassing the knowledge base, knowledge accumulation and dissemination activities, and knowledge management. The basic framework of our model is presented in Fig. 2 and the constituent parts are illustrated in more detail in Figs 3, 4 and 5. The basic elements and ideas of the framework will be explained subsequently.

\section{The knowledge base}

Previously we have defined knowledge as internalized information that has value for the organization. This knowledge is stored in what we call the organization's knowledge base. This knowledge base can consist of many media (sources), which we have grouped in four categories (adapted from Zeleny et al. (1990) and Boer \& Krabbendam (1991)):

brainware: knowledge in the mind of people, such as experience, intuition, a person's educational background;

hardware: touchable things incorporating knowledge, such as solid prototypes, products, R\&D equipment, production processes;

groupware: unwritten knowledge shared by people, such as rules of thumb, procedures, stories;

documentware: knowledge documented on paper or in databases/information systems, such as CAD/CAM models, parts database, patents, lab reports, handbooks.

Looking from the perspective of a researcher, the organization's knowledge 


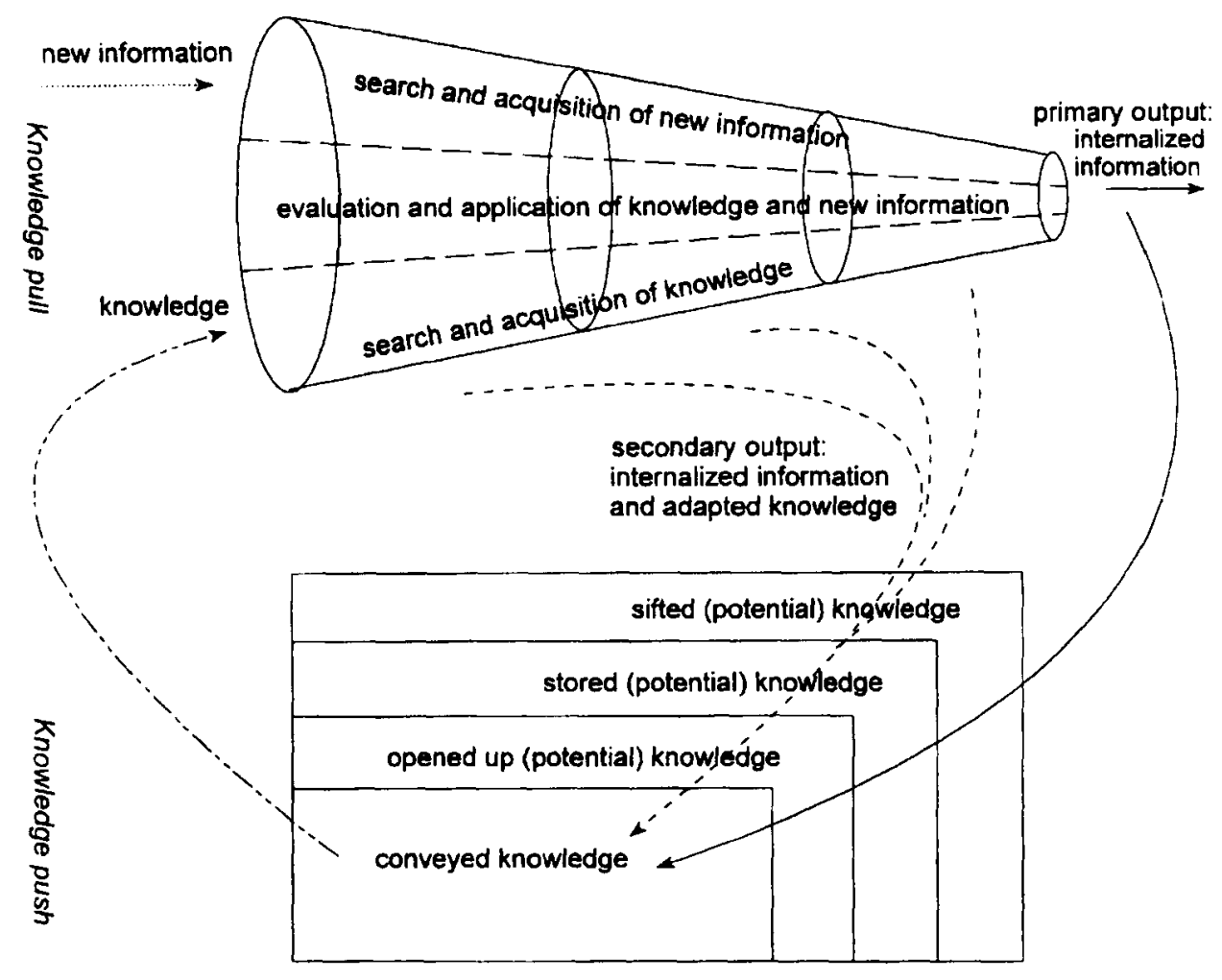

Figure 4. Knowledge accumulation and dissemination activities in the R\&D process

base consists of several layers (see Fig. 3). Although not depicted in the figure, one should also note that the knowledge base contains both task-specific (technical, marketing, etc.) and managerial knowledge. Unfortunately, in many R\&D organizations the largest part of the knowledge is stored in the least traceable and accessible medium: the brainware, which makes it difficult to deploy the knowledge optimally. More importantly, it makes the company very dependent on individual researchers.

\section{The $R \& D$ project funnel and the primary $R \& D$ output}

Figure 4 visualizes R\&D projects and activities as a funnel with different stages, referring to the gradual uncertainty reduction by means of new acquired information from outside the company, and knowledge from the organizational knowledge base. Next to the search for, and acquisition of, new information and knowledge, the creative work of learning and transforming these inputs into new meaningful outputs, takes place in the funnel, including the evaluation and application of information and knowledge. R\&D projects and activities are expected to deliver, at least, the intended primary $R \& D$ output, being 'internalized information' in some transferable form. For example, for an applied research project this output could be a document describing a new technology and its relevant application areas, for a development project a proven product/process design, a working prototype and a written product introduction plan, and for technical support activities a document or an oral message giving the answer to a specific problem.

Secondary output

Next to the primary output, $R \& D$ projects and activities often also deliver other valuable outputs. These outputs range from new information about characteristics of materials or components, techniques that failed or 
succeeded to deliver the intended output, etc., up to information about how (or not) to communicate with people from Manufacturing, usability of a planning tool or the information that customer $\mathrm{X}$ is willing to participate in future field tests. Thus, the nature of these outputs can be technical, managerial, marketing, etc. Those pieces of information that are expected to be relevant in the future, should be sifted and recorded.

\section{Knowledge handling}

With the term 'knowledge handling' we refer to the activities of sifting (potential) knowledge from many pieces of internalized information, storing this knowledge, opening it up and conveying it to a user. These activities should provide the knowledge to researchers carrying out their projects and facilitate the acquisition. Input for these activities is the primary and secondary internalized information coming from R\&D activities. The knowledge handling activities can be explained as follows:

Sifting: because much information is generated, it is not possible to store everything, so sifting information that has the potential to be applicable many times in the future, is needed. As said earlier, a clear (long term) R\&D strategy is necessary to do this properly. It should be noted that sifting can be done explicitly, e.g. by means of post project audits, but many times it will be done implicitly, especially in the case of brainware and groupware.

Storing: of potential knowledge uses one of the media (sources) of the knowledge base. As with sifting, storing can be done explicitly or implicitly. The choice of a particular medium and the number of media in which the knowledge is stored, is very important as it determines to a great extent the possibilities of opening up the information.

Opening up: means making knowledge traceable and easily accessible by others. If you do not know that a certain colleague has a particular piece of knowledge, you will not use it, although you may talk with this person regularly. On the other hand, it can also happen that you know a piece of knowledge is in a certain report, but you cannot get access to it because the report is confidential. So both traceability and accessibility are important conditions for reuse of knowledge.

\begin{tabular}{|c|c|c|c|}
\hline $\begin{array}{c}\text { R\&D } \\
\text { performance } \\
\text { criteria }\end{array}$ & $\begin{array}{c}\text { R\&D } \\
\text { process } \\
\text { design }\end{array}$ & $\begin{array}{c}\text { R\&D } \\
\text { technology } \\
\text { design }\end{array}$ & $\begin{array}{c}\text { R\&D } \\
\begin{array}{c}\text { organisation } \\
\text { design }\end{array}\end{array}$ \\
\hline $\begin{array}{l}\text { Innovation and learning } \\
\text { performance criteria } \\
\text { Hours spent on early } \\
\text { information acquisition } \\
\text { total project hours }\end{array}$ & $\begin{array}{l}\text { R\&D process } \\
\text { Innovativeness (basic } \\
\text { research...technical support) } \\
\text { Complexity (single product } \\
\text { process or technology } \\
\text {...multiple) } \\
\text { Size (small..large in terms } \\
\text { of time and budget) } \\
\text { Technological areas (e.g. } \\
\text { electronics, pharmaceutics) } \\
\text { Process phases (concept } \\
\text { development...project } \\
\text { evaluation) } \\
\text { Strategic, adaptive and } \\
\text { operational (R\&D) } \\
\text { management processes }\end{array}$ & $\begin{array}{l}\text { People } \\
\text { Number of people (per } \\
\text { unit) } \\
\text { Personal networks } \\
\text { Drivers of motivation } \\
\text { Personal qualities (e.g. } \\
\text { communication skills) } \\
\text { Traceability and } \\
\text { accessibility of people } \\
\text { Tools } \\
\text { Communication tools (e.g. } \\
\text { QFD) } \\
\text { Equipment } \\
\text { Kind and volume of IT } \\
\text { equipment (e.g. databases } \\
\text { E-mail) } \\
\text { Functionality of IT } \\
\text { equipment } \\
\text { Accessibility of equipment }\end{array}$ & $\begin{array}{l}\text { Structure } \\
\text { Physical distance between } \\
\text { units / team members, etc. } \\
\text { Performance appraisal } \\
\text { system } \\
\text { Project coordination } \\
\text { mechanisms (e.g. multi- } \\
\text { functional project teams) } \\
\text { Transfer mechanisms (e.g. } \\
\text { people transfer, inter- } \\
\text { mediaries) } \\
\text { Group constitution (e.g. } \\
\text { average tenure) } \\
\text { Culture } \\
\text { Interfunctional climate } \\
\text { Informal contacts } \\
\text { Communication (e.g. } \\
\text { feedback) } \\
\text { Management attention (e.g } \\
\text { knowledge transfer } \\
\text { explicitly encouraged) } \\
\text { People roles (e.g. gate- } \\
\text { keeper) }\end{array}$ \\
\hline
\end{tabular}

Figure 5. Influential characteristics of the R\&D strategy on knowledge accumulation and dissemination 
Conveying: refers to the actual 'handing over' of knowledge to another person (or yourself at a later point in time!). This can be done in several ways, e.g. by remembering (brainware delivered to yourself!), by communication (brainware and software), by observation (hardware and software), by examination (hardware) or by reading (documentware).

\section{Knowledge management}

As stated in the introduction, knowledge management is part of the R\&D strategy. The decisions made in the $R \& D$ strategy determine the possibilities and barriers to sift, store, open-up, convey, search for, and apply potential knowledge. In the literature overview, we have identified many R\&D strategy characteristics that influence the performing of these activities. These characteristics are summarized in Fig. 5.

If we look at the aims of knowledge management, two areas warranting attention can be identified. First, knowledge management is aimed at improving what might be called knowledge push, the knowledge handling activities described in the lower half of Fig. 4. By applying knowledge management mechanisms one will try to limit the energy spent on information which in the end turns out to be 'one time use' only, and minimize loss of knowledge (see Fig. 6). Second, knowledge management also aims at improving what might be called the knowledge pull, the activities depicted in the upper part of Fig. 4.

\section{Use of the descriptive model}

In the previous section we have introduced our descriptive model of knowledge, knowledge activities and knowledge management. In this paragraph we will discuss two possible uses of such a descriptive model. For the first application we refer to the cybernetics literature on process control, for example, de Leeuw (1982) has stated that for effective control of a process, a managing system has to meet the following requirements:

it has to specify the goals the process will aim at and use these goals as guidelines for management;

it has to have a model of the process, describing how internal and external disturbances and management measures can influence the behaviour of the process; it has to have information about the actual situation of the process and the relevant variables in the environment;

it must have a sufficient variety of corrective measures.

Thus, to effectively manage knowledge accumulation and dissemination in the R\&D process, managers need to have a model of the activities of knowledge handling, knowledge acquisition and application, the place of these activities in the general $R \& D$ process and the internal and external factors and management measures that influence them. The framework presented in this article can serve for this purpose: Figs 3 and 4 give insights into the process and from the most influential knowledge management

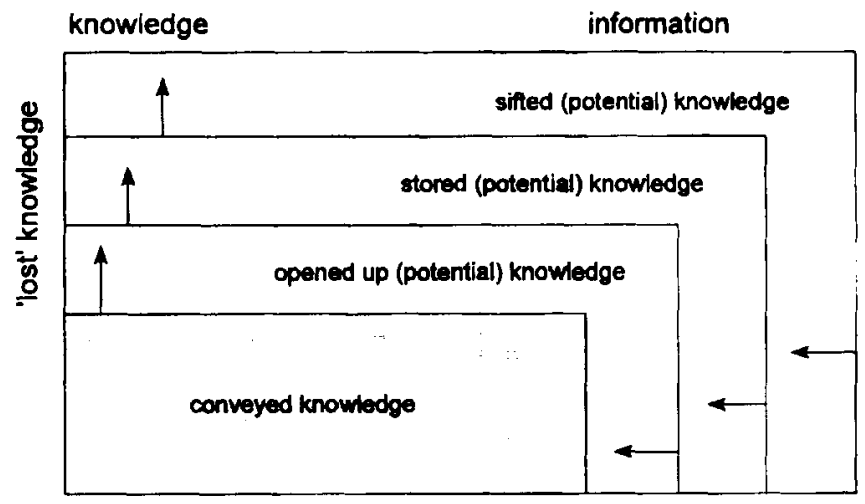

Figure 6. The aims of knowledge management concerning knowledge handling 
characteristics in the R\&D strategy, which are listed in Fig. 5, management measures can be derived.

Furthermore, a simple model or framework can be a helpful instrument to make an organization think about and discuss the way in which its $R \& D$ (knowledge) activities are managed (Wheelwright \& Clark, 1992; Debackere et al. 1994), and act as an aid in formulating improvement plans. Below we describe a case study in which we used our model in such a way, by carrying out the following steps.

\section{Describe overall business}

Especially when the model is applied by someone from outside the company (a researcher or a consultant), first of all some basic information should be collected on aspects such as: the organization's legal status and structure, main products, number of employees, market and competition characteristics, positioning of the R\&D process in the organization. Furthermore, by filling in columns $1-4$ from the Operations Strategy Framework (Fig. 1), the overall business strategy with which the R\&D strategy should align can be summarized.

\section{Mapping the knowledge base}

The concept of the 'organizational knowledge base' (Fig. 3), can help to identify and categorize the knowledge sources available, and those actually used by researchers for different types of projects, in different project phases, etc. This mapping can be done by interviewing the employees. Table 1 gives an example of a knowledge base map. The mapping could be enhanced by also asking the frequency of use and the value of the sources in solving specific problems. Results can be compared with findings in literature and common perceptions, and possible bottlenecks can be identified.

\section{Mapping knowledge push and pull activities}

By interviewing or discussing, one can identify and map the knowledge push and pull activities carried out explicitly or implicitly by the researchers, and the means used for these activities. The model in Fig. 4 could serve as a checklist. This way, weak points in the knowledge accumulation and dissemination process, such as badly performed or neglected activities, can be revealed. The resulting map should thus list the search, acquisition, evaluation and application activities of knowledge (knowledge pull), as well as the knowledge push activities: sifting, storing, opening up and conveying.

\section{Mapping influential $R \& D$ strategy characteristics}

Many of the choices made in the R\&D strategy will either positively or negatively influence knowledge accumulation and dissemination. The literature overview and Fig. 5 in this article list many such aspects. They could thus serve as checklists for mapping the influential R\&D strategy characteristics. This should result in an overview of the current knowledge management practice and of the R\&D strategy choices that actually harm knowledge accumulation and dissemination.

Table 1 Example of a knowledge base map

\begin{tabular}{|c|c|c|c|c|}
\hline & Brainware & Documentware & Hardware & Groupware \\
\hline Personal & Memory & Personal archive & Computer tools & $\begin{array}{l}\text { See below, known to } \\
\text { individual }\end{array}$ \\
\hline Group & R\&D colleagues & $\begin{array}{l}\text { Handbook, group } \\
\text { archive }\end{array}$ & R\&D equipment & $R \& D$ rules of thumb \\
\hline Location & $R \& D$ colleagues & Central archive & Prototypes & $\begin{array}{l}\text { Project management } \\
\text { procedures }\end{array}$ \\
\hline R\&D org. & R\&D colleagues & $\begin{array}{l}\text { Library, repons from } \\
\text { other locations }\end{array}$ & $\begin{array}{l}\text { Competitors' } \\
\text { products }\end{array}$ & $\begin{array}{l}\text { Success and failure } \\
\text { stories }\end{array}$ \\
\hline Company & $\begin{array}{l}\text { BU managers, } \\
\text { production engineers }\end{array}$ & $\begin{array}{l}\text { Marketing data, } \\
\text { production data }\end{array}$ & $\begin{array}{l}\text { Current products, } \\
\text { processes }\end{array}$ & $\begin{array}{l}\text { Production rules of } \\
\text { thumb }\end{array}$ \\
\hline
\end{tabular}




\section{Identification of bottlenecks and supporting formulation of improvement plans}

The three mapping activities mentioned above in steps $2-4$, related to the overall business strategy summarized in step 1, should result in an overview of weak points in the knowledge accumulation and dissemination process and in the management of this process. The descriptive model presented in this paper and the literature overview on which the model is built, give some suggestions as to how these could be improved.

\section{KNOWLEDGE MANAGEMENT AT THE PTR GROUP OF CHEMCO}

We have applied our descriptive model in a case study concerning the process technology research group of a Dutch multinational company in the chemical industry (further referred to as the PTR group and Chemco respectively). Our aims with this case study were twofold: testing and improving our descriptive model, and giving the PTR management advice on how to improve their knowledge management. Time constraints and the limited insight of PTR management into the actual status of knowledge accumulation and dissemination, made us decide to limit ourselves to the steps mentioned in Table 2. The corresponding steps, as mentioned in the previous paragraph, are indicated in italics. The results of these steps will be briefly discussed in the subsequent paragraphs. Note that we chose to look in more detail at activities aimed at opening up (potential) knowledge (step 5), which was explicitly requested by Chemco. Chemco's R\&D activities are carried out at different locations and therefore they had a specific interest in the issue of how to make (potential) knowledge available (traceable and accessible) between these different locations. Note also that the description was restricted to the project start up phase since at Chemco this was considered to be the phase in which the most knowledge accumulation and dissemination activities occur.

\section{Chemco and the PTR group}

Chemco is a large, diversified company in the chemical industry, with production plants in several countries and sales all over the world. The R\&D function of Chemco is

Table 2 Research activities in the case study

\begin{tabular}{|c|c|c|}
\hline Step & Activities & Data input \\
\hline 1. & $\begin{array}{l}\text { Characterization of Chemco and the PTR group } \\
\text { (describing overall business) }\end{array}$ & In-depth interviews with PTR manager \\
\hline 2. & $\begin{array}{l}\text { Description of the knowledge base } \\
\text { (mapping the knowledge base) }\end{array}$ & $\begin{array}{l}\text { ldem }+30 \text { interviews with researchers at } 3 \\
\text { locations and on-site observations }\end{array}$ \\
\hline 3. & $\begin{array}{l}\text { Description of information/knowledge search } \\
\text { in the project start-up phase and how this is } \\
\text { managed } \\
\text { (mapping knowledge pull activities and } \\
\text { influential aspects in R\&D strategy) }\end{array}$ & Idem \\
\hline 4. & $\begin{array}{l}\text { Description of the knowledge handling activities } \\
\text { iin general and how this is managed } \\
\text { (mapping knowledge push activities and } \\
\text { influential aspects in R\&D strategy) }\end{array}$ & Idem \\
\hline 5. & $\begin{array}{l}\text { Description how knowledge is opened up } \\
\text { (mapping one of the knowledge push activities } \\
\text { in more detail) }\end{array}$ & Idem \\
\hline 6. & $\begin{array}{l}\text { Analysis and identification of bottlenecks } \\
\text { (identification of bottlenecks etc.) }\end{array}$ & Data from previous steps \\
\hline 7. & $\begin{array}{l}\text { Formulation of improvement plans } \\
\text { (idem) }\end{array}$ & Idem + three benchmarking interviews \\
\hline
\end{tabular}


divided between several countries, including The Netherlands where Chemco has several research locations. Until recently, each corporate division had one or more divisional research units, working closely together with the production plants. Furthermore, there were two central research facilities where larger research projects were carried out. Research units were managed as cost centres. However, recently, the R\&D strategy was changed to create more synergy, improve cooperation and reduce costs. The $R \& D$ organization is now structured into four technical disciplines, each encompassing several research sites that were formerly dedicated to specific Business Units (BUs). Furthermore, the R\&D units are now considered to be service centres, which should raise their own funds by working for the BUs. The BUs are made responsible for both short and long term $R \& D$, so they are supposed to define clear business plans on which the $R \& D$ strategy should be based. Within $R \& D$, account managers are assigned to coordinate the entire research programme for a certain BU.

The PTR group is responsible for the research activities concerning production processes for fibres and chemicals. The group has about 200 employees and is divided in three subgroups, located at different sites (locations A, B, and C). As a result of historical factors, each of these locations is more or less specialized in a certain type of research, and the mix of organizational arrangements clearly differs. PTR activities are mainly organized as projects, managed by a project leader from the PTR group. Chemco has started with multifunctional project teams, but this is not yet very wide-spread. Formal transfer of information from and to BUs is primarily done by the account manager (called the Programme Coordinator), whose counterpart in the BU is the Technology Manager. But there are also informal contacts at the individual level. As part of the corporate change programme, the following actions have been formulated and (partly) implemented by the PTR management:

Consolidation of the three process technology research units into one group;

Closing down one location and moving the researchers to one of the other sites;
Expanding the use of multifunctional project teams;

Establishing a situation of undercapacity in BU dedicated research groups, thus forcing them to ask knowledgeable researchers from other groups to take part in their projects;

Pushing BUs to formulate long term business plans that can guide the R\&D strategy.

\section{The knowledge base and information/knowledge search}

In the project start-up phase the following information/knowledge search activities were identified:

establishing the problem and research objectives;

determining the current situation in the production process;

determining the theoretical knowledge on this process;

determining the direction in which the solution should be sought.

Furthermore, a distinction was made in types of project. Overall, the types of sources used, and their relative importance in each step and for the different project types, were in line with other investigations given in literature. The PTR researchers strongly rely on brainware. However, the use of outside information is remarkably low, especially for the more innovative projects. Next to this, the use of knowledge from other $R \& D$ locations (documentware and brainware) is limited. Some researchers indicated that they feel a bit embarrassed to ask their fellow researchers for help, and see it as a challenge to solve problems themselves. We also noted that there is no specific stimulus for extensive information/knowledge search, e.g. by means of rewarding knowledge seeking behaviour in the performance appraisal system. One might even state that, until recently, there was a negative stimulus, as each location was assessed upon their own budget coverage. Thus, spending your own resources to solve problems was rewarded more highly than asking more knowledgeable people from another location for help. Since all the PTR locations have recently been merged into one group, this 'system- 
technical' problem is solved. However, the 'social-dynamic' problem of forming one team out of people used to working separately, remains.

\section{Knowledge handling}

At the moment, the $B U$ strategies are not sufficiently known by the researchers to serve as a 'sifting guideline', nor is there a specific stimulus from management to sift and store the generated (potential) knowledge. The choice of media and the ways in which potential knowledge is opened up, is generally left to individual researchers or groups. Thus, there is a great difference between locations. For example, in location $\mathrm{A}$, most of the produced documentware is expected to be recorded in the central database, and thus traceable and accessible. In location B, databases are only used locally. On the other hand, brainware is much less open in A than in the other locations, as the groups at location A have little contacts with each other.

\section{Opening up}

Brainware and documentware inside the location are mostly traced and obtained by experience and self search, while brainware and documentware at other locations are usually traced and accessed via colleagues. Thus, opening up heavily relies on the social-dynamic functioning of the organization and individuals. The most used systemtechnical means of tracing and accessing knowledge is the formal group and function name (e.g. the function 'Technology Manager' suggests that this person knows the problems and needs of a BU). The use of this reference means is moderate. Documentware in the library and the central archive is sometimes traced and obtained by means of information services. When used, researchers are quite satisfied with these services. Overall, traceability of sources is quite problematic, especially of sources in other locations.

\section{Bottlenecks and recommendations}

In Table 3, the main bottlenecks in knowledge handling and searching in the PTR group are summarized. As previously mentioned, the PTR management has already formulated improvement plans, which might also help reduce the bottlenecks. In the second column of the table their expected impact is indicated (numbers refer to actions mentioned in the paragraph on Chemco and the PTR group). In the third column we mention additional improvement plans that emerged in the discussions with PTR management.

So far, all the presented improvements were of a system-technical nature. However, as already indicated in the analysis, many problems need changes in the social-dynamic system, which are much more difficult to achieve. The attitude of the researchers has to change in favour of knowledge accumulation and dissemination. The first step is that the researchers must be made aware of the

Table 3 Bottlenecks and improvement plans

\begin{tabular}{|c|c|c|}
\hline Bottleneck & Actions started & Additional actions \\
\hline No clear strategy to guide sifting & 5 & \\
\hline Opening up of knowledge & $1,2,3,4$ & $\begin{array}{l}\text { Logical division of tasks over groups and } \\
\text { functions, and self-explaining names } \\
\text { Set up intermediary, e.g. Who-knows-what } \\
\text { database or help desk } \\
\text { Store all documentware in one central } \\
\text { computer database, including documentware } \\
\text { from Production/Marketing }\end{array}$ \\
\hline $\begin{array}{l}\text { Researchers' attitude not attuned to } \\
\text { actively exchange knowledge }\end{array}$ & & $\begin{array}{l}\text { Adapt the performance appraisal system by } \\
\text { including an indicator for knowledge use }\end{array}$ \\
\hline No explicit knowledge management & & $\begin{array}{l}\text { All actions mentioned are part of a first attempt } \\
\text { to explicitly manage knowledge }\end{array}$ \\
\hline
\end{tabular}


importance of this issue, and feel that management considers this to be really important. Next to this, project leaders must stimulate knowledge search and should be made responsible for the conveying of knowledge within the team and to others. To improve the building of personal networks, job rotation and multigroup project teams should be encouraged. Finally, formal and informal group contacts should be explicitly considered and stimulated as opportunities to exchange knowledge.

\section{CONCLUSIONS AND FURTHER RESEARCH}

Above, we have discussed the development of a descriptive model for knowledge management and illustrated its use in a case study. The model ties together the different concepts of knowledge and clarifies the relationships between issues that are in some way felt to be related to knowledge management, such as information technology and organizational learning. It should be noted that, as $R \& D$ processes are in essence information transformation processes, knowledge accumulation and dissemination activities are in fact embedded in the mainstream R\&D process. Also, knowledge management is largely based on mechanisms, such as multifunctional project teams, which are also aimed at other purposes (e.g. improving quality or speeding up the R\&D process). Our descriptive model illuminates these specific knowledge accumulation and dissemination activities within the $R \& D$ process and the influential R\&D strategy characteristics and makes managers aware of them. This awareness is a first step towards effective control of knowledge accumulation and dissemination in the $R \& D$ process.

In the paper, we have also proposed a second application of a descriptive model: as a communication and analysis tool. In the case study, we have tested the usefulness of our model for this purpose. We can conclude that the model proved to be helpful in several ways:

as a means to focus and structure the data gathering and analysis;

as a communication tool between the authors and PTR management; as an analysing tool to identify the bottlenecks;

as a lead for formulating improvement plans.

Furthermore, we used a preliminary version of the model as a framework for discussions in a workshop on knowledge management. Here, it helped to link and frame the different concepts of knowledge and knowledge management held by the participants. The explicit distinction made between the knowledge handling activities was found to help in clarifying ideas.

However, the case-study and workshop discussions also illuminated some weak points in the model, especially in the area of the social-dynamic functioning of $R \& D$ organizations. It is quite possible to define and apply system-technical measures (see table 4), but their success still depends on the social-dynamic functioning of the organization. The model was found to be accurate in identifying social-dynamic bottlenecks, but unfortunately it gave little help in finding concrete solutions to these problems. Getting a grasp on the role and the working of experience, intuition, group dynamics, etc. in knowledge management would be a major improvement. This remains an area for further research.

We conclude that the model is a starting point for the development of a practical communication and analysis tool that can be used by researchers, consultants and $R \& D$ managers as a means to assess the current situation and to uncover bottlenecks in knowledge management. In further developing the model, the following has to be taken into account. We learned that managers still found the model rather complex and sometimes had difficulties in interpreting the concepts used. A better focus on the most important contributing factors is needed. To develop it further towards a diagnostic instrument, better operationalization is needed and morphologies have to be developed describing consistent, successful sets of processes, technologies and organizational arrangements supporting knowledge accumulation and dissemination. Also, it is important that the model can be used for self-assessment, so that R\&D managers are not dependent upon a researcher or consultant for its use. This demands that application of the model should 
be far less time consuming and simplicity should be strived for as much as possible.

\section{ACKNOWLEDGMENTS}

The authors gratefully acknowledge the help of Nard Roodenrijs, the empirical findings in the case study are largely drawn from his graduation assignment carried out for Chemco. Furthermore, we thank the anonymous referees of R\&D Management for their useful comments.

\section{REFERENCES}

Allen, T. J. (1977), 'Managing the Flow of Technology', Cambridge MA: M.I.T. Press.

Argyris, C. and Schön, D. A. (1978), 'Organizational Learning', Reading MA: Addison-Wesley.

Ashton, W. B. and Stacey, G. S. (1995), Technical intelligence in business: understanding technology threats and opportunities' Int. J. Technology Manogement, Vol. 10, No. 1.Boer, H. and Krabbendam, J. J. (1991), 'Organizing for market oriented manufacture', paper presented at the POMS Conference. New York City, USA, November $11-13$.

Brown, S.L. and Eisenhardt, K. M. (1995), 'Product development: past research, present findings, and future directions', Acadeny of Management Review, Vol. 20. No. 2. 343-378.

Clark, K. B. and Fujimoto, T. (1991), Product Development Performance, Boston: Harvard Business School Press.

Debackere, K., Fleurent, I., Vanderheyden, K. and Huiskens, L. M. (1994), 'Managing the knowledge portfolio: a critical asset for successful new product development', paper presented at the 2nd International Product Development Management Conference on New Approaches to Development and Engineering. Gothenburg. Sweden, May 30-31.

Fiol, C. M. and Lyles, M. A. (1985), 'Organizational learning'. Academy of Management Review, Vol. 10, No. 4.

Hauptman, O. (1986), "Influence of task type on the relationship between communication and performance: the case of software development', $R \& D$ Management, Vol. 16, No. 2

Hauser, J. R. and Clausing, D. (1988). 'The house of quality', $H B R$, May-June, p. 63-76.

Jain, R. K. and Triandis, H. C. (1990), Managemem of Research and Development Organizations. Managing the Unmanageable, New York: Wiley \& Sons.

Johnston, R and Gibbons, M. (1975), 'Characteristics of information usage in technological innovation', IEEE Transactions on Engineering Management, Vol. 22, No. i.
Katz, R. and Allen, T. J. (1982), 'Investigating the Not Invented Here (NIH) syndrome: a look at the performance, tenure, and communication patterns of 50 R\&D Project Groups', R\&D Management, Vol. 12, No. 1.

Ketley, A. D. (1994), 'Managing information in a Japanese laboratory', Research Technology Management, Nov-Dec.

Kim, D. H. (1993), 'The link between individual and organizational leaming', Sloan Management Review, Autumn.

Kumpe, T. and Bolwijn, P. T. (1994). "Towards the innovative firm-challenge for R\&D management'. Research Technology Management, Vol. 37, No. 1.

Lee, D. M. S. (1994). 'Social ties, task-related communication and first job performance of young engineers', J. Eng. and Technology Management, No. 11, p. 203-228.

Leeuw, A. C. J. de (1982), Organisaties: managemtent, analyse, ontwerp en verandering: een systeemvisie, Assen, The Netherlands: van Gorcum (In Dutch).

Meyers, P. W. and Wilemon, D. (1989), 'Learning in new technology development teams', Journal of Product and Innovation Management, No. 6. 79-88.

Moenaert, R. K, Deschoolmeester, D.,De Meyer, A. and Souder, W. E. (1992), "Information styles of marketing and R\&D personnel during technological product innovation projects', $R \& D$ Management, Vol. 22, No. 1.

Moenaert, R. K. and Souder, W. E. (1990), 'An information transfer model for integrating marketing and $R \& D$ personnel in new product development projects', Journal of Product and Innovation Management, No. 7, 91-107.

Souder, W. E., Nashar, A. S. and Padmanabhan, V. (1990), 'A guide to the best technology-transfer practices', Technology Transfer, Winter-Spring.

Takeuchi, H. and Nonaka, I. (1986), 'The new product development game', Harvard Business Review, Jan-Feb.

Weerd-Nederhof, P. C. de, Fisscher, O. A. M. and Kerssens-van Drongelen, I. C. (1995), 'Managing quality in R\&D: socialdynamical aspects and the importance of generating (new) organizational configurations', in C.Young (ed.), 'Unraveling the complexity of new product design, development and commercialization', academic presentations at the PDMA Conference, Bloomington Minnesota, USA, October 10 , 1995

Weerd-Nederhof, P. C. de, Kerssens-van Drongelen, I. C. and Verganti, R. (1994), 'Pan I: R\&D management', Coursebook Managing the R\&D Process, Enschede, The Netherlands: Twente Quality Centre.

Weerd-Nederhof, P. C. de, Boer, H., Fisscher, O. A. M. and Gieskes, J. F. B. (1996), Assessing R\&D quality. Towards a descriptive model of R\&D systems, context and quality performance', 1996 R\&D Management Conference on Quality and $R \& D$, University of Twente. Enschede, the Netherlands, 6-8 March 1996.

Wheelwright, S. C. and Clark, K. B. (1992), 'Revolutionizing Product Development', New York: The Free Press.

Zeleny, M., Cornet, R. J. and Stoner, J. A. F. (1990), 'Moving from the Age of Specialization to the Era of Integration', Human Systems Management. Vol. 9, p. 153-17. 


\section{APPENDIX I}

Table 4 R\&D management matrix

\begin{tabular}{|c|c|c|c|}
\hline & & \multicolumn{2}{|c|}{ ORGANIZE } \\
\hline \multicolumn{2}{|c|}{ R\&D MANAGEMENT } & System-technical & Social-dynamic \\
\hline \multirow[t]{2}{*}{ CONTROL } & Operational & $\begin{array}{l}\text { - Division of tasks, responsibility and } \\
\text { authorities } \\
\text { - Composing project teams } \\
\text { - Phasing and structuring projects } \\
\text { - Using planning methods and } \\
\text { reporting structures }\end{array}$ & $\begin{array}{l}\text { - Communication and consultation } \\
\text { - Motivation and commitment } \\
\text { - Team building }\end{array}$ \\
\hline & Strategic & $\begin{array}{l}\text { - Positioning R\&D inside the company } \\
\text { - Strategic choices: } \\
\text { Which environment, markets } \\
\text { - Which emphases as regards content } \\
\text { etc.? } \\
\text { - Long-range planning (e.g. } \\
\text { budgeting) } \\
\text { - Determine strategic alliances }\end{array}$ & $\begin{array}{l}\text { - Shared values and standards } \\
\text { - Dynamic decision making }\end{array}$ \\
\hline
\end{tabular}

Source: Weerd-Nederhof et al. (1995). 